\title{
A revolução copernicana de Kant
}

\author{
Kant's Copernican Revolution
}

\author{
JULIANA GILO TIBÉRIO
}

\begin{abstract}
Resumo: O artigo visa, apenas, situar, sumariamente, o sentido e o alcance da assim chamada "revolução copernicana" operada por Kant na Crítica da Razão Pura como uma espécie de divisor de águas no contexto de uma nova teoria do conhecimento como contraponto crítico da metafisica.
\end{abstract}

Palavras-chave: Kant. Revolução copernicana. Razão.

Abstract: The article aims only to summarize the meaning and scope of the so - called "Copernican revolution" operated by Kant in the Critique of Pure Reason as a sort of watershed in the context of a new theory of knowledge as a critical counterpoint to metaphysics.

Keywords: Kant. Copernican Revolution. Reason.

\section{Introdução}

O presente texto tem por objetivo clarificar como a obra do filósofo alemão Immanuel Kant foi um divisor de águas para filosofia moderna. Ora, esse divisor pode bem ser circunscrito por aquilo que ele denomina "revolução copernicana" operada no nível de uma teoria do conhecimento a partir de uma crítica à metafísica.

É o que passaremos, sumariamente, em revista, agora.

\section{A revolução copernicana na Crítica da Razão Pura}

Na obra Crítica da Razão Pura, especificamente, no prefácio da segunda edição, Kant apresenta uma "revolução" importante no pensamento filosófico na era moderna. O que levou Kant a produzir essa "crítica" da razão foi a imprecisão da metafísica dogmática no trato com todos os assuntos: ele questionou a incerteza de suas conclusões, o fato de que até então não se estabeleceu se a metafísica “[...] está ou não no caminho seguro de uma ciência [...]” (KANT, 2015, p. 25, CRP B VII).

No entanto, o filósofo não sugere um novo sistema, mas antes uma mudança de método: em vez de adequar a razão humana ao objeto, como nas filosofias anteriores, Kant propõe que o objeto se adeque à razão; este método é inspirado na chamada revolução copernicana, agora aplicada à filosofia. O termo "revolução copernicana" vem do cientista da natureza, Copérnico, que propõe a passagem do antropocentrismo ao heliocentrismo.

\footnotetext{
${ }^{1}$ Graduada em Filosofia pela UNIOESTE. E-mail: juh_ana_gt@hotmail.com.
} 
No sentido de remover o objeto do centro das atenções, Kant propõe para a metafísica alocar o sujeito no centro, fazendo com que os objetos girem à sua volta. Por essa operação Kant examina com a maior liberdade possível as condições ínsitas no sujeito, no conjunto das operações por ele previamente executadas, a fim de constituir as possibilidades do conhecimento dos objetos materiais.

De início, Kant constatou que a matemática e a física haviam seguido um caminho de sucesso desde seu surgimento; pergunta então por que a metafísica não teve o mesmo sucesso que a matemática e a física: essas (matemática e a física) haviam seguido desde cedo essa revolução no modo de pensar, em que o sujeito ocupa o centro e em que é privilegiada a capacidade de conhecer com relação aos objetos. Consequentemente, o que levou as ciências em geral a um caminho seguro e ao progresso foi o elemento racional presente nelas: esse racional vem da forma (ou das condições de possibilidade) com que o sujeito conhece seu objeto. Diz Kant:

A tarefa principal desta crítica da razão pura especulativa reside nessa tentativa de modificar o procedimento até hoje adotado na metafísica, e isso de tal modo que operemos uma verdadeira revolução da mesma a partir do exemplo dos geômetras e dos pesquisadores da natureza (KANT, 2015, p. 33, CRP BXXII).

Portanto, com essa inversão de método, em que o objeto se regula pelo sujeito do ponto de vista tanto sensível (formas puras da sensibilidade) quanto inteligível (conceitos do entendimento), acentua-se a estrutura do conhecimento (do objeto) como assentada no sujeito. Assim, a obra kantiana critica a tradição, no marco de um estudo metafísico prévio à proposta da revolução copernicana e em outro estudo metafísico iniciado a partir dessa revolução: seu objetivo é um projeto na qual se fundamenta, diz Silva: "[...] qualquer tipo de saber em nível transcendental [...]" (SILVA, 2016, p. 24). Por isso deixa evidente que a metafísica no sentido tradicional não alcançou o sucesso que espera-se a essa atual, afirma Kant: "O destino não foi até agora tão benevolente com a metafísica, um conhecimento especulativo da razão inteiramente isolado, que se eleva por completo para além dos ensinamentos da experiência” (KANT, 2015, p. 28, CRP B XIV, grifo do autor), pois, até que a razão se autoesclareça, será necessário à “ [...] metafísica [...] voltar inúmeras vezes sobre o caminho, pois se percebe que ela não conduz aonde se quer chegar”(KANT, 2015, p. 29, CRP B XIV). Por isso, conclui ele dizendo: “[...] não há nenhuma dúvida [...] de que o seu procedimento foi até aqui um tatear às cegas e, o que é pior, um tatear entre conceitos puros" (KANT, 2015, p. 29, CRP B XV).

A fim de defender a sua perspectiva da razão desde uma investigação pura e transcendental, dirá Kant (2015, p. 29-30, CRP B XVI):

É preciso verificar pelo menos uma vez, portanto, se não nos sairemos melhor, nas tarefas da metafísica, assumindo que os objetos têm de regular-se por nosso conhecimento, o que já se 
coaduna melhor com a possibilidade, aí visada, de um conhecimento a priori dos mesmos capaz de estabelecer algo sobre os objetos antes que nos sejam dados.

Quando fala da metafísica, Kant refere-se a um conhecimento especulativo que ultrapassa a experiência, mas menos no sentido de propor - como na metafísica tradicional - um conhecimento elevado para além da sensibilidade - do que um conhecimento das condições puras e a priori que fundamentam todas as estruturas sensíveis e intelectuais que exprimem a relação necessária de nossos conceitos para a sua referência objetiva empírica. Daí que essa metafísica se distingue da tradicional, que é considerada um conhecimento teórico "[...] que procura o seu objeto fora da experiência mediante simples conceitos, sem se referir nunca a objetos" (SILVA, 2016, p. 25).

Para exemplo, pode-se utilizar de exemplo a existência de Deus, enquanto um conceito clássico da metafísica. Isto é, Kant salva os conceitos da metafísica dogmática (Deus, alma e liberdade) buscando tematizá-los desde essa perspectiva crítica. Como afirma Silva (2016, p. 25):

Deus consistindo em um conceito vazio em termos de experiência é um problema que está para além da experiência possível. Ao pensar na demonstração da existência de um ser supremo, trata-se, segundo Kant, de meros conceitos para quais nunca se encontrou objetos adequado na experiência.

Embora seus predecessores houvessem tentado tratar teoricamente da determinação desses conceitos como o de Deus, afirma, segundo Kant a metafísica deve deixar de ser meramente um campo de batalha, no qual não pode haver vencedor ou perdedor. Pois, para cada um (diríamos: para cada abordagem unilateral, ou meramente racional, ou meramente empírica), não se pode conceder a verdade. Por isso, enquanto mantida a metafísica como esse campo de batalha, a disputa só tinha por caminho fazer voltar inúmeras vezes para rever o seu fundamento. Afirma Kant (2015, p. 29, CRP B XIV-BXV):

[...] no que diz respeito à unanimidade de seus defensores nas afirmações que fazem, ela [metafísica] está tão longe disso que mais parece um campo de batalha, um campo destinado a exercitar as forças em jogos de combate, mas onde até hoje nenhum combatente conseguiu conquistar o menos lugar para si, nem fundar uma posse duradoura a partir de uma vitória.

Nota-se que a metafísica tateou conceitos vazios, que não possuem referência à natureza (matéria empírica). Mas a questão central a investigação kantiana busca elucidar é a seguinte; diz: Silva "[...] como pode a metafísica ser o campo de maior interesse da razão e mesmo assim ela nunca conseguir provar uma verdade sequer?" (SILVA, 2016, p. 27). 
A resposta a isso se ligada ao fato de que a metafísica para Kant aponta para um horizonte de maior complexidade do que se supunha. Em vez de ela apontar somente para a possibilidade de um conhecimento verdadeiro, Kant descobre nela a tarefa mais ampla de conceber a distinção entre "conhecer" - o fenômeno (o que se mostra) - e "pensar" - o númeno (o que não se mostra, mas é um dever pensar). É desde a inversão de perspectiva, relativo à metafísica dogmática, que Kant dá os primeiros passos para resolver essa questão. A saber, através da revolução copernicana aplicada na filosofia.

O modelo da metafísica tradicional mostrava a razão como dependente de uma objetividade previamente admitida, pela qual o sujeito devia se orientar, tanto do ponto de vista dos sentidos quanto dos conceitos. Daí que devia ser conduzida a inversão de lugar do objeto e do sujeito: se na metafísica tradicional o sujeito se regulava pela natureza do objeto - onde a razão se mostra como meramente receptora e em nada autora da experiência cognitiva -, para Kant o sujeito deve assumir o lugar central na constituição do conhecimento e da experiência. Observa ele:

É preciso verificar pelo menos uma vez, portanto, se não nos sairemos melhor, nas tarefas da metafísica, assumindo que os objetos têm de regular-se por nosso conhecimento, o que já se coaduna melhor com a possibilidade, aí visada, de um conhecimento a priori dos mesmos capaz de estabelecer algo sobre os objetos antes que nos sejam dados (KANT, 2015, p. 29-30, CRP, B XIV).

Nessa direção se propõe que todo conhecimento deve se regular pela natureza do sujeito (de suas estruturas e faculdades puras a priori), de modo a considera a precedência disso que jaz a priori como elemento exclusivo da razão, com cuja explicação se obtém mais facilmente elucidar a possibilidade de um conhecimento de objetos.

Daí se mostrar insustentável a tese da realidade em si das coisas, independentemente de o sujeito ser afetado por elas; antes, assenta nas regras que constituem as faculdades subjetivas as condições para se pronunciar sobre $o$ conhecimento objetivo. Nesse sentido a noção mesma de objeto de conhecimento é constituída pela razão e deve sê-lo. Por exemplo: a intuição ${ }^{2}$ da sensibilidade percebe os objetos que aparecem no espaço e no tempo ${ }^{3}$ e produz sensações relativas à representação dos mesmos. Dessa forma o mundo é conhecido através da sensibilidade e não como ele é (ou possa ser) em si mesmo.

\section{Considerações finais}

\footnotetext{
${ }^{2}$ A intuição é a capacidade de perceber os objetos pelos sentidos.

${ }^{3} \mathrm{O}$ espaço e o tempo são formas puras a priori do sujeito.
} 
Quando fala em revolução copernicana, Kant remete por analogia à teoria de Copérnico, não havendo a necessidade de compreender totalmente o geocentrismo ou o heliocentrismo. $\mathrm{O}$ que o filósofo alemão faz é então aplicar essa mudança de método para alcançar o que até agora não havia sido obtido pela metafísica, a saber, elucidar os limites da razão no conhecimento e no pensamento.

Se até então a metafísica fora um simples tatear às cegas, sem conseguir explicar nem mesmo seus principais conceitos (Deus, alma, liberdade), com Kant volta-se para o sujeito para estabelecer a partir dele o verdadeiro método da metafísica. Como diz Silva:

Através da revolução proposta por Kant será possível à compreensão de que as formas dos objetos não estão nos próprios objetos, mas são elas contribuições da razão para a constituição do objeto. Em outros termos, o mundo é percebido pelos sentidos não é como ele é em si mesmo, mas como o homem o representa a partir da estrutura formal da sua mente, das suas capacidades (SILVIA, 2016, p. 34).

Em vista disso, por essa ruptura com a tradição filosófica, a razão transcendental vem mostrar a sua autonomia com respeito à constituição do terreno da experiência e de sua fundação a partir do conhecimento a priori ${ }^{4}$, visto que, afirma Silva, "[...] a razão só reconhece o formal que é dela mesma segundo a qual ela organiza tanto os objetos quanto os conceitos, quantos a sua própria natureza" (SILVA, 2016, p. 34).

Destarte, a razão se regula a ela mesma e não ao objeto, encontrando por isso um caminho seguro para a metafísica. Observa o filósofo alemão:

No que diz respeito à primeira parte da metafísica, em que ela se ocupa de conceitos a priori para os quais podem ser dados na experiência os objetos correspondentes, essa tentativa é tão bemsucedida quando poderíamos esperar e promete a metafísica o caminho seguro de uma ciência (KANT, 2015, p. 31, CRP B XVIIIBXIX).

Conclui-se assim reafirmando o papel decisivo da revolução copernicana à história da filosofia moderna pelo esclarecimento proporcionado aos objetivos da razão.

\section{Referências}

KANT, I. Crítica da Razão Pura. Tradução e notas de Fernando Costa Mattos. 4. ed. Petrópolis, RJ: Vozes; Bragança Paulista, SP: Universitária São Francisco, 2015. (Coleção Pensamento Humano)

\footnotetext{
${ }^{4}$ A priori é todo o conhecimento que antecede toda a experiência.
} 
SILVA, F. A. "A revolução copernicana na filosofia de Kant: breves considerações a partir do Prefácio da segunda edição da Crítica da razão pura”, in: Enciclopédia: revista de filosofia, v. 6, p. 22-35, 2016.

Submissão: 30.08.2018 / Aceite: 20.10.2018. 